\title{
Spatial transfer of innovations: South-South learning on village-scale solar power supply between India and Kenya
}

\author{
Kirsten Ulsrud, Harald Rohracher and Charles Muchunku
}

\begin{abstract}
This article presents research on the transfer of sustainable energy innovations between countries of the global South from a socio-technical perspective. The analysis identifies factors important for how a deliberate transfer process may unfold. It is based on monitoring a case of South-South transfer of experiences with village-level solar power supply models from India to Kenya. This research shows that it is not so much stable technical solutions which travel between different spatial and cultural contexts, but that experiences with sustainable technologies in one country can provide important inspiration and knowledge for the development of new socio-technical designs based on local needs in a new socio-spatial context in a different country. Such learning processes can be especially effective between countries with similar problem situations, such as poverty and lacking access to electricity in rural areas. To achieve a successful transfer, strong emphasis must be put on mutual learning and exchange of knowledge, sociotechnical experimentation, adaptation and social embedding. Learning from promising, innovative infrastructures in other geographical areas needs to capture the micro-level interactions between people, technology and socio-cultural contexts, while also taking into account larger processes of system innovation and emerging transitions.
\end{abstract}

\section{Introduction}

Existing examples of social and technological changes, whether successful or not, are valuable sources of learning for those who seek societal improvement (Hoogma et al. 2002, Kalleberg 2009, Raven et al. 2008). Many pioneering and innovative activities are currently taking place globally in order to develop a greener and more equitable society. In the field of electricity supply for instance, attempts to develop solutions that can reach all parts of the population in sustainable ways can be found in many countries, not least within off-grid use of renewable energy technologies in the Global South. There is geographical diversity in the details of such experimentation at the same time as they are addressing similar problems. This 
creates a potential for transferring practical experience and knowledge between these activities in countries of the Global South.

However, technologies and their configurations are parts of wider socio-technical systems developed and embedded in specific geographical and cultural contexts, thus they are not likely to be directly transferable to different places (Raven et al. 2008). Technologies are closely interwoven with social practices, actors and institutions involved in their production and use (Berkhout et al. 2010). Although institutions shape the framework conditions for involved actors, it is difficult to reproduce institutional conditions that govern the field of energy in other places. Moreover, it has been pointed out that donors and funders of technology projects in developing countries do not always put sufficient effort into understanding the recipient society, the actual needs of people and the details of what fits to a specific social context (Murphy 2001, Ockwell \& Byrne 2017).The dynamic relations between the social and technical dimensions in different geographical contexts have been widely recognized (Bridge et al. 2011, Metz et al. 2000, Romijn \& Caniëls 2011).

Although some kind of translation is clearly necessary, spatial and contextual aspects of technology transfer have received little attention in research, policy and practice so far. Technology transfer was earlier mostly understood as a unidirectional, linear process of delivering technology, expertise and financing to a country from the outside, especially from the Global North to the Global South (Maskus 2004). Such an understanding has long been questioned (Metz et al. 2002), but is still typical for the way technology transfer is considered today, for instance in relation to climate change (Ockwell and Byrne 2017). The transfer of social and technological innovations between different socio-cultural contexts and national settings remains poorly understood. This includes how an adaptation or translation of innovations to different social contexts may take place, and which kinds of factors influence such processes.

This article discusses insights from a socio-technical transfer process where processes of learning through "trying, failing and trying again" were explored as a mechanism for the gradual adaptation to contextual conditions. Drawing on experiences with the transfer of solar mini-grids from India to Kenya, the paper investigates how a spatial transfer strategy can combine different kinds of knowledge, including local knowledge and experience, to facilitate a creative learning process. Village-level solar power systems, like solar mini-grids are a good example of how decentralized, small-scale renewable energy models can potentially contribute to an equitable and sustainable transition of energy systems. Our analysis of the 
effects of an ongoing system innovation in Kenya highlights how a planned South-South transfer of innovations can offer deliberate, stepwise transfer strategies that can potentially link energy transition processes in different countries facing similar problems.

In the following section 2 we present the theoretical approach to this analysis followed by a description of the case and how it was studied in section 3 . The results are analyzed in section 4 and 5 , and conclusions are suggested in section 6 .

\section{Theoretical approach}

Two bodies of literature particularly discuss the spatial transfer of technology or socio-technical systems. The first is the literature on technology transfer to countries in the global South, and the other analyses concepts of inter-local learning in the growth of socio-technical niches. Even if the second one has mainly been developed in a European context, we find it relevant for understanding strategic efforts for transferring socio-technical innovations between local initiatives in the South.

\subsection{Literature on technology transfer to countries in the South}

A large part of the literature on international technology transfer to countries in the South has focused on how developing countries can catch up with industrialized countries in technological advancement, industrial production and production of their own capital goods, as well as large-scale energy and water supply (Maskus 2004). Channels for technology transfer between countries identified in this literature include trade in products, trade in knowledge, direct foreign investment, and international movement of people. The transfer has traditionally been assumed to go from North to South. Central issues discussed are the policies of technology exporting countries, spillover effects from foreign direct investment, protection of infant industries and competition issues. Authors also focus on norms and standards set by multilateral organizations, trade terms and intellectual property rights (Bell \& Albu 1999; Grübler \& Nakićenović 1991; Hoekman et al. 2004; Reddy \& Zhao 1990; Soete 1985). Such literature on technology transfer only provides limited insights on the transfer of knowledge, experience and equipment relevant for implementation and use of technology in local communities, which is the focus here.

More specific literature in this field relates to the transfer of "clean technologies" to combat climate change and the same time create economic and social development in the South. Some of this literature has developed a more integrated view on social and technical dimensions (Halsnæs et al. 2007; Martinot et al. 1997). A special report from IPCC (Metz et al. 2000) conceives of technology transfer as a broad set 
of processes covering the flows of know-how, experience and equipment. It also comprises processes of learning to utilize and replicate technology, including the capacity to adapt it to local conditions and integrate it with indigenous technologies. Participatory approaches and strengthening of networks are suggested elements, and it is recommended not to ignore late stages of the transfer process. The report emphasizes the sustainable development perspective of technology transfer, i.e. the importance of creating social and economic development at the same time as addressing climate change and other environmental problems, which is also pointed out by Román et al. (2012).

Barriers to technology transfer mentioned in this literature are especially related to the characteristics of the "recipient" or "host country", including human and institutional capacity and science and educational infrastructure. A lack of ability to develop and replicate innovations is addressed. So-called "active technological behavior" by technology importing firms is called for to avoid technological dependence and stagnation. Emphasis is put on the characteristics of the "recipient", including ability to absorb and use new technology efficiently (Halsnæs et al. 2007; Metz et al. 2000).

Some of this literature has come as a reaction to the way technology transfer is seen in practice within international mechanisms for technology transfer, such as the Clean Development Mechanism (CDM). Byrne et al. (2011) and Ockwell \& Byrne (2017) argue that the current form of CDM seems to be influenced by an understanding of technology as "hardware", with some understanding of the need for "software", mainly in terms of cooperation and maintenance skills. A range of societal problems are assumed to get solved through such mechanisms for transfer of low-carbon technologies, including problems of energy access, equity, security, and environment. However, considerations of social conditions and economic realities of the people who could benefit from the technological change are often insufficient (Murphy 2001).

\section{2 "Inter-local learning" - technology transfer as learning between projects}

The concept of "inter-local learning" is used to address learning between projects both within and between countries. The concept is relevant for our analysis of technology transfer, even though it is not focusing explicitly on international technology transfer to developing countries. According to Raven et al. (2008), inter-local learning means learning between specific socio-technical experiments in different geographical contexts - practical projects where new technologies or new ways of using technologies are tried out in real-life settings. The work on inter-local learning is part of a broader effort to understand the formation of socio-technical niches, their accumulation and impact on transitions towards more 
environmentally sustainable systems. Local experiments contribute to the formation of niches which often are radically different from existing mainstream systems or regimes, such as the conventional energy system (Raven et al. 2008; Schot \& Geels 2008).

Such experiments draw on experiences from similar projects, and represent local variations of the emerging structures or rules of a socio-technical niche. An important aspect is local re-invention in order to embed the project in the social context. Such embeddedness is created through establishing continuity with existing physical, social and cognitive structures and by providing local benefits. Locally appropriate communication and participation procedures are also suggested (Raven et al. 2008, p. 469). Local benefits may include energy independence or creation of a new marketable product, local employment, and improvement of community services (Raven et al. 2008; Späth \& Rohracher 2012). This is relevant for direct learning between projects, which is important here.

Figure 1 below shows learning processes between the local socio-technical experiments (projects) and the aggregate niche level as well as between local projects (Coenen et al. 2010, p. 297; Geels \& Raven 2006). The mechanisms shown in the figure represent processes of building up socio-technical systems in niches, of which inter-local learning is just one element. This article is particularly interested in the potential for systematic knowledge sharing and learning between specific projects in different places and countries, marked by bold arrows in the figure. Such learning from one project to another is likely at the same time to be influenced by the trends in the broader niche, the established socio-technical regimes and the broader social contexts in different geographical areas at multiple geographical levels.

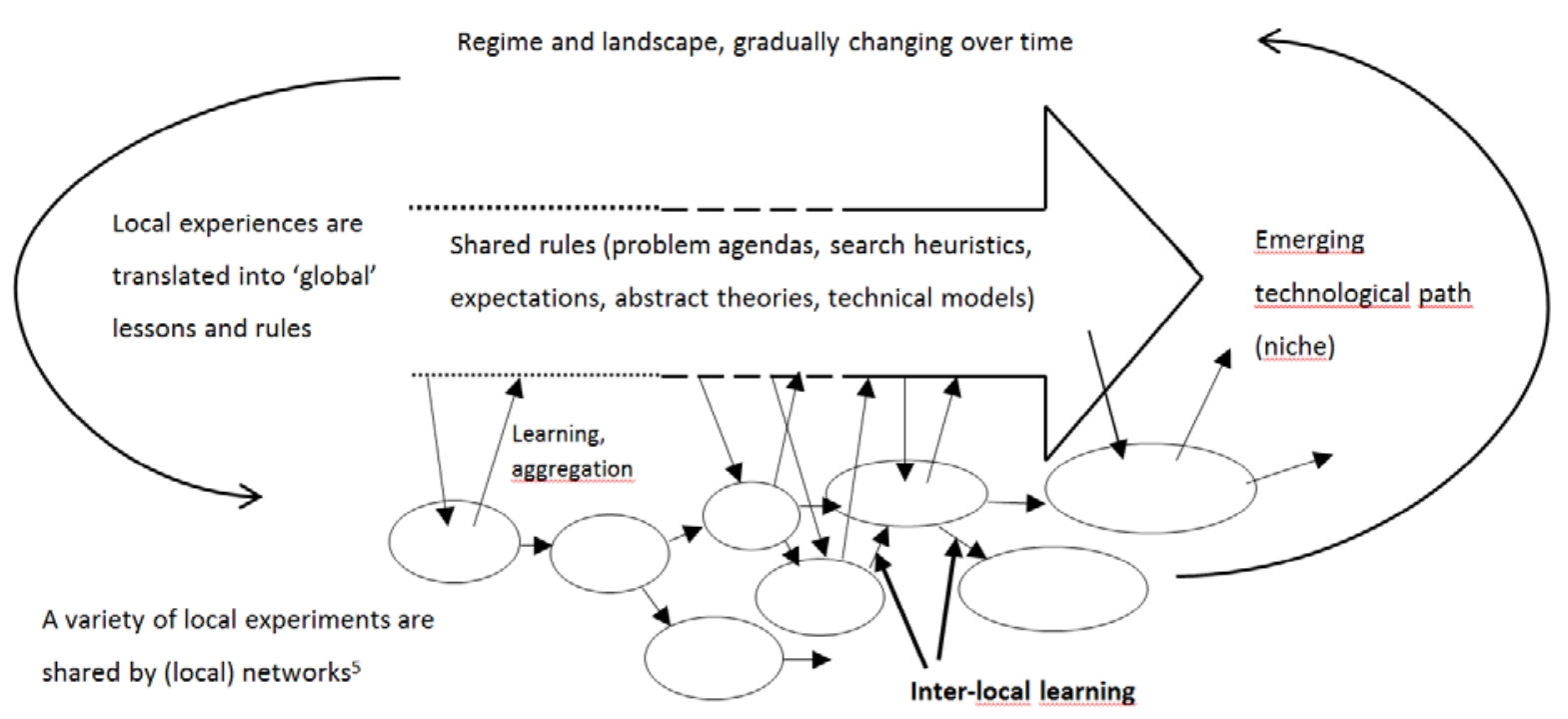


Figure 1. Inter-local learning and aggregation of lessons learned (emerging niche), based on Coenen et al. (2010) and Geels and Raven (2006)

The process of investigating socio-technical innovations in India in order to develop a project in Kenya can be seen as a case of inter-local learning across two countries. Although inter-local learning has been considered important for socio-technical innovation, there has been little elaboration on how it could be organized and utilized in strategic and effective ways. This paper contributes to filling this gap, and suggests ways of enhancing sensitivity to local context and local embeddedness of projects, which seem to be key aspects for success of such transfer of innovations.

\section{Methods used to document the process}

The transfer process of village-scale solar energy systems between India and Kenya was studied and documented over six years through active participation. This research is based on a qualitative methodology, suitable for achieving in-depth understanding of social processes in terms of how they unfold and why. A variety of data sources and methods have been used, including notes on the process, project documents, e-mails between group members, and meeting reports. Other data are letters to the village community and conversations with Kenyan participants in a study tour to India. Group members' reflections on the way the strategy worked have also been documented.

Action research, in terms of active participation in the process, which can be used as an extension of qualitative methods, gave a special opportunity to understand the transfer process from the inside out (Herr and Anderson 2005, Karlson and Larrea 2014). As insiders in this process, we made in-depth and detailed observations of factors that played a role for how the transfer process worked. The participation in the process provided an opportunity to trace the process as it came into being.

In addition to the data described above, the results of the case study in India are also important for our understanding of the process in terms of how the insights obtained in India were taken into account in the Kenyan project. These data include eleven expert interviews in New Delhi and Kolkata, 31 qualitative interviews in six villages and a quantitative survey of 200 households (Ulsrud et al. 2011). Furthermore, the data collected on the emerging power supply implemented in Kenya gave a detailed understanding of the outcomes. The data include 70 survey interviews in 2010, comprehensive and repeated participatory observation, GPS mapping of a village, collection of monthly financial reports, notes from staff and board 
meetings, and a quantitative survey in 2015 with 1100 households and small businesses (Ulsrud et al. 2015). The time period covered by this analysis is from 2009 up to spring 2017.

\section{Analysis of the transfer process and its outcomes}

The transfer project was a social science-led, transdisciplinary and international research project with two aims: firstly, to contribute to new knowledge on how solar power can be socially organized in order to contribute to better and more widespread access to electricity and secondly to study how a spatial transfer of innovations could take place in context-sensitive ways. One specific type of socio-technical configuration was selected for the study, solar mini-grids, a way of using solar photovoltaic (solar PV) technologies at the village scale instead of so-called 'solar home systems' used at the household level. Village-scale systems are better suited to facilitate income generation through the use of electricity and provide collective village services like IT and TV, they free individual users from investments and maintenance, and they provide more flexibility for households to vary their consumption. The work was led by the University of Oslo and funded by the Research Council of Norway. The funding covered the costs of travelling, networking and practical planning and implementation in addition to the normal research activities, but not the technical equipment and buildings.

Even if the idea of learning from Indian off-grid solar energy applications and transferring them to Kenya initially came from an outsider, the University of Oslo, it was early on supported by several Kenyan "niche actors" working on the use of solar power. These actors were located in the 'middle level' of the energy sector where they worked as researchers, consultants or government officials (see Janda and Parag, 2013), and some of them became members of the project team. These actors were highly interested to get a chance to study examples of solar mini-grids in India and experiment with new ideas for solar power use in Kenya. In the further process, this team also connected with the local community and government administration in a Kenyan village which strongly supported the idea. In addition, a Kenyan "regime" actor linked up with the project on his own initiative, a middle level official from the Kenyan electricity utility. At the same time an Indian partner, centrally placed in the Indian solar PV sector, became a team member.

\subsection{Different socio-technical systems for use of solar power in India and Kenya}

Important similarities between India and Kenya as well as a range of other countries in the Global South are that large parts of the population are not connected to the electricity grid. According to the OECD and IEA (2017), 239 million people in India and 17 million people in Kenya are without electricity access. In addition, a large number of households connected to the electricity grid suffer from unreliable or non- 
functional supply (World Bank and IEA 2013). At the same time many pioneering and innovative activities and attempts of up-scaling are going on in the South in order to develop accessible, affordable and viable models (Wieczorek et al. 2015). India was selected for this research because experiments with solar minigrids had been going on for a many years and India was among the leading countries for the decentralized use of solar power (Palit 2013). Kenya was selected because there were actors who were motivated to join the suggested transfer project. The interest of Kenyans working with solar power to study Indian experiences on solar mini-grids which did not exist in Kenya played an important role in the set-up of the project. Kenya was also seen as interesting because the country had one of the best developed markets for solar PV household systems in Sub-Saharan Africa (Jacobson 2007, Byrne 2009, GTZ 2009).

In India, the government had actively promoted solar technology through subsidies and institutions devoted to implement renewable energy. Partly therefore, the Indian solar PV niche had a higher diversity of models for the delivery of electricity from solar PV, including solar mini-grids. In Kenya, the diffusion of solar systems had been mainly driven by the private market with donors giving important support (Ockwell and Byrne 2017). Activities in Kenya were mainly focused on small household systems, while some larger systems were used at tourist camps, and the government had begun to install solar systems at boarding schools and health clinics. While the Indian government's involvement in solar and other renewable energy was institutionalized in a separate Ministry and state agencies, the Kenyan work was less anchored within the government. However, small units dealing with these technologies existed within the Ministry of Energy and the Rural Electrification Authority.

Both countries have a "split" energy regime, like many other developing countries - a conventional electricity sector that supplies electricity to parts of the population, and off-grid systems, which are still to a large extent based on diesel generators, kerosene lamps, candles and firewood. These traditional technologies have started to be replaced by renewable off-grid electricity provision such as solar home systems. Despite fast growth of these technologies in Kenya and other countries in the South, off-grid solar PV still is a niche technology. Most of the actors linked to these technologies are separate from the incumbent electricity system and in general smaller and less powerful than those in the centralized electricity sector. Moreover, off-grid applications are less institutionalized, regulated by a rather weak legal framework, and less prioritized by governments, financial interests and companies. 


\subsection{Analyzing the social and institutional contexts}

The starting point of the South-South technology transfer project was the assumption that solar mini-grids could be a potentially useful strategy for off-grid electricity supply in Kenya, in addition to solar home systems, because of various useful features of mini-grids as mentioned above. Solar mini-grids in India seemed to be a promising model, and learning opportunities between these countries appeared promising because both faced similar challenges in infrastructure provision. The ambitious aim was to create a well-functioning, up-scalable model of solar mini-grids in Kenya that others could build on in order to strengthen decentralized electricity supply. The research team was just a temporary organization, so the idea was to create a model which could be taken up by the private sector or the government.

As pointed out in the conceptual part of this paper, such a transfer needs to be understood not only as an exchange of technologies, but as a transfer of socio-technical systems with strong attention to social and human dimensions of these configurations. Social science-led case studies were thus part of the transfer project to help understand the current socio-technical systems of off-grid electricity supply and their contextual conditions, as well as the context where the new activities would take place. Contextual differences were expected to influence the transfer process and its outcomes. The socio-technical framework of analysis developed to study existing applications and their implementation in new contexts was as follows:

Firstly, an analysis of context conditions - the national framework of energy policies and politics, ideologies, regulations and strategies for local infrastructure development. The assumption was that the context of the existing energy system as well as the characteristics of the emerging solar PV and renewable energy niches (within the respective countries but also globally) would play an important role for what was possible to implement and operate on the ground.

Secondly, in order to understand the characteristics and functioning of a local infrastructure system/technology project, it is necessary to understand it as part of a local, socio-cultural context of livelihoods, social practices, socio-economic conditions, settlement patterns, gender relations and social norms. These kinds of factors influence the practical functioning of the local infrastructure, and the match of the new technology with local conditions.

Thirdly, detailed information on the socio-technical design of the local electricity supply systems was required, both the technical details and the non-technical dimensions (organizational, economic and other 
social aspects), as well as the underlying reasons for this design, including the visions and ideologies behind it and the influence from national and international environments.

Fourthly, the most central dimension to understand was how the system was actually used in practice, including service delivery, daily operation, maintenance, management, and economic sustainability. The intention is to better understand unexpected outcomes and their dependence on different circumstances, since the way a socio-technical innovation like an off-grid solar system works in practice will always be different from how it is meant to work ideally. This has been convincingly shown by other scholars in social studies of technology and socio-technical transitions (Russell and Williams 2002, Stirling 2008).

Fifthly, the characteristics of the electricity services need to be studied, e.g. which types of services are provided, to whom, and why. Issues like reliability, affordability, and physical/spatial accessibility in different areas of the community were central.

\subsection{Technology transfer as an iterative and comprehensive learning process}

The analysis of the actual process of transferring solar mini-grids from India to Kenya is structured along the flow of events. Theoretically spoken, it shows a gradual process of contextualizing (and re-inventing) a village-level solar power model in Kenya based on inputs from solar mini-grids in India and from other relevant background knowledge. It can also be described as a creative, iterative and comprehensive learning process through a socio-technical experiment embedded in the Kenyan solar PV niche but inspired by examples in India and elsewhere.

The activities had their beginning in Kenya, based on previous experience with solar PV and off-grid electricity provision and the specific needs for access to electricity in rural areas. The steps of the transfer strategy are listed in table 1 below, showing how they overlapped in time. In parallel with these steps, the project group monitored and contributed to "spin-off" activities inspired by the core activities. In the following, we explain how the process unfolded and how certain outcomes were achieved.

Table 1. The main activities carried out for the development of a power supply model in Kenya.

\begin{tabular}{|l|l|l|l|l|l|l|l|}
\hline & $\begin{array}{l}\text { The activities that made up the Kenyan case, } \\
\text { including the process of learning from India }\end{array}$ & $\begin{array}{l}2006- \\
2008\end{array}$ & 2009 & 2010 & 2011 & 2012 & $\begin{array}{l}2013- \\
2017\end{array}$ \\
\hline & Preparations with Kenyan energy experts & & & & & & \\
\hline & Research and study tour in India, analysis & & & & & & \\
\hline & Selection of place in Kenya & & & & & & \\
\hline & Studies of the national context in Kenya & & & & & & \\
\hline & Studies of the local context in Kenya & & & & & & \\
\hline
\end{tabular}




\begin{tabular}{|l|l|l|l|l|l|l|l|}
\hline Cooperation with Kenyan village & & & & & & \\
\hline & Development of system design & & & & & & \\
\hline & Procurement, training, start-up & & & & & & \\
\hline Follow-up, support and advice, local level & & & & & & \\
\hline & Research on viability of the model & & & & & & \\
\hline
\end{tabular}

Early on, the project group had several meetings with actors in this field in Kenya, including private and public sector and civil society. One purpose was to get the different actors' views on the current state of off-grid electricity supply, and their needs and plans to carry out new activities. The project group informed relevant actors, for instance the Ministry of Energy, and sought inputs and comments in an attempt to make the project more relevant for them.

A significant step was to select a place in Kenya for the pilot project, and there were several geographical areas where mini-grids would be relevant. While a mini-grid business would have chosen the place with the most promising potential for earning revenue in order to sustain the power supply economically and to make a profit, the members of this project in the end decided to select a place with so-called little potential, but representing a large number of un-electrified places in Kenya and elsewhere - Ikisaya village in Kitui County. An important ambition was nevertheless to achieve an economically sustainable model.

The research and study tour in India was only carried out after most of these initial steps in Kenya had taken place, because the initial planning and networking in Kenya was expected to give ideas for what kind of information from India could become relevant for the Kenyan pilot project. The group had chosen one specific cluster of mini-grids as a source for learning. They had been implemented by a state agency, West Bengal Renewable Energy Development Agency (WBREDA) in the Sunderban Islands in India in the delta of the river Ganges. The according program in West-Bengal had operated for many years, and thus presented a good opportunity to learn from a long period of experience. 17 solar mini-grids had been implemented from 1996 onwards serving 300-500 customers each on different islands. Electricity was provided for some hours in the evening, mainly for light, phone charging, TV, fans and other low-power appliances. The group also benefitted from the Indian partner's (TERI - The Energy and Resources Institute) ability to recruit several Indian experts on off-grid use of solar PV in India for a joint workshop in Kolkata. The project group had invited extra guests from Kenya to give them first-hand impressions of mini-grids and establish co-operations. 
"Seeing is believing" was a repeated comment of the participating Kenyan partners. Compared with solar home systems the mini-grids looked impressive and gave inspiration. Some of the participants at the same time commented on some poor quality electronic installations in the Indian power plants and poor maintenance. The Kenyan participants had no doubt they would have the capacity to set up such plants in Kenya, and better than this, with better economic performance. The participants exchanged ideas and plans underway, inspired by what they saw. The Indian project partner added a component by bringing the group to visit solar charging stations also for renting of portable lanterns partly initiated by themselves.

A thorough case study in India gave a comprehensive picture of how the mini-grids worked and which challenges they faced. For instance, since sufficiently cheap and robust metering technology was lacking, people paid a fixed amount per month for a certain number of appliances used in the evening. However, people also developed practices for using as much electricity as possible despite these restrictions, which in turn reduced revenue and increased maintenance costs because overuse harmed the large battery banks. This in turn gave people poor service and reasons for not paying. The operators were supposed to take care of the power plants for the state agency, but many of them lacked the motivation and incentive to do so. The research interviews in the villages gave a deep understanding of these and many other aspects of the case. The socio-cultural context locally was characterized by poverty and irregular incomes, struggles to deal with frequent cyclones that damaged the land, houses and other assets. The Sunderban mini-grids would not have existed without government funding of the initial investment and they were also dependent on support for operation. Some of the Kenyan team members pointed out that such government involvement would not be realistic in Kenya, where there was a strong focus on market principles among leading actors in the electricity supply.

Jointly studying the Indian mini-grids turned out to be a reference point for the development of villagescale energy innovations in Kenya. The project members used the Indian example as a background and pointed to it in discussions in order to support various arguments, not least on needs to do things differently. Eventually the Indian team member's familiarity with charging stations became also highly important during the following process.

Innovative solutions were required in Ikisaya due to pitfalls identified in the Sunderban mini-grid projects, and because the team decided to select this village in Kenya despite the contextual differences from the Sunderban villages. It was gradually realized by the group that not only the settlement patterns but also the high poverty level in the selected geographical area made a mini-grid project unsuitable for a place 
like Ikisaya and a large number of other places in Kenya and Sub-Saharan Africa. A mini-grid would reach only a small part of the population in such places and have much higher operation costs than the potential revenue due to people's low ability to pay. Therefore, after initial attempts to design some kind of minigrid with wires to the nearest buildings and portable services for others, the idea for an "Energy Centre" came up.

The Energy Centre would still be a solar power plant delivering electricity services at the village-level, just without electricity grid. Thus the electricity had to be used at the Centre (at the power plant) or taken home by charging portable devices. People's wishes for light, phone charging, IT services and TV could be served, while other ideas would require a much larger power plant. The size of the power plant was small and appliances energy-efficient in order to reduce expenses for battery replacement and maintenance. The group had learned from India that a large battery bank would be a threat to economic sustainability. The implemented design in the end had similarities but also differences to the charging station model in India. This shift from mini-grid to charging station was not least due to the liberty of the Kenyan and Indian project partners to experiment with designs and try out ideas, a situation that is rare under the guidance of central funding organizations. Also the flexibility to make changes after implementation was perceived as a great advantage by the partners. The planning process for the practical project in Kenya nevertheless took long time. Much emphasis was put on the "socio-technical design" phase and adaptations required in this process turned out to be more comprehensive than expected.

The resulting socio-technical design for the Ikisaya model differed significantly from both models seen in India, the thoroughly studied mini-grids and the briefly observed solar lantern charging stations. The following table shows how far the Kenyan village-scale power supply configuration was gradually led away from the original design in India through a long process of learning and reflection because of the need to adapt the Kenyan system to very different conditions.

The main differences between the Sunderban model and the Ikisaya model

\begin{tabular}{|l|l|}
\hline The solar mini-grids studied in India & $\begin{array}{l}\text { The socio-technical design for the project in } \\
\text { Kenya }\end{array}$ \\
\hline Gridlines to the houses & No gridlines \\
\hline $\begin{array}{l}\text { Power supplied for fixed hours in the evening for } \\
\text { lighting, phone charging, TV and fans. } \\
\begin{array}{l}\text { Photocopying and typing services provided by } \\
\text { electricity customers }\end{array}\end{array}$ & $\begin{array}{l}\text { Power used when needed, but for limited time, } \\
\text { typing, and TV services. Retail shop at the power } \\
\text { plant }\end{array}$ \\
\hline
\end{tabular}




\begin{tabular}{|l|l|}
\hline $\begin{array}{l}\text { Monthly payment for electricity, fixed amount } \\
\text { at two levels }\end{array}$ & $\begin{array}{l}\text { Payment upfront for each service, no fixed } \\
\text { payment }\end{array}$ \\
\hline $\begin{array}{l}\text { Large system (relatively), 25-110 kW for 300-500 } \\
\text { households and other customers }\end{array}$ & $\begin{array}{l}\text { Small system, 2.1 kW for lighting for 240 } \\
\text { households and various services }\end{array}$ \\
\hline $\begin{array}{l}\text { 1-2 operators in a plant, mainly doing technical } \\
\text { tasks, but also negotiating with local people } \\
\text { (committees, customers, etc.) about problems }\end{array}$ & $\begin{array}{l}\text { 3-4 staff members, doing a variety of tasks. The } \\
\text { customers and the staff meet face to face every } \\
\text { time the customers uses the services }\end{array}$ \\
\hline $\begin{array}{l}\text { Staff has little freedom to influence the } \\
\text { business, but their commitment is important for } \\
\text { the technical performance of the electricity } \\
\text { provision }\end{array}$ & $\begin{array}{l}\text { Staff has large freedom to influence the business, } \\
\text { and large responsibility for the viability of the } \\
\text { system }\end{array}$ \\
\hline Only men as staff & $\begin{array}{l}\text { Women and men as staff } \\
\text { implementer owns the technical equipment }\end{array}$ \\
\hline Owned by the government & \\
\hline
\end{tabular}

There were still important similarities. For instance, both models were village-scale models based on delivery of electricity services to the citizens, both entailed a solar power plant with battery storage and allocation of limited amounts of electricity between different types of electricity services, and both had local staff in the villages with responsibility for the operation.

The pilot project in Ikisaya village in Kenya was implemented in 2012, after training of the local staff and board from the village, installation and start-up. The operation of the system went as planned, but even such a small system was difficult to sustain economically (i.e. to save enough money for battery replacements and other maintenance), and making the services affordable for the households was more difficult than anticipated. However, operational routines and the economic performance incrementally improved during continued cooperation, research and learning after implementation. Despite thorough work in order to anticipate early on how the energy system would work, a good understanding only developed after experiencing how the new services suited to people's everyday life practices and which new practices emerged in relation to electricity provision.

\subsection{Impact beyond the pilot transfer project}

A core idea of organizing technology transfer via collaborative pilot projects is to have a longer term impact in the recipient country which leads to a further uptake and possibly scaling up of the technology. In our case two government activities were inspired by the visit in India and ensuing transfer efforts.

The first of these activities was the installation of solar power in conventional isolated power grids (also 
called mini-grids) in Kenya, run by large diesel generators, and turning them into hybrid power plants. These were owned by the Ministry of Energy and operated by Kenya Power. The Kenya Power engineer had tried to develop plans for a solar PV trial before the trip to India, because some solar PV panels were available after the close down of a school project, but these plans had been rejected by the Ministry. The Indian mini-grids provided the necessary information for the engineer to convince the Ministry through a report that described solutions to some of the uncertainties and missing pieces of his first proposal, and showed pictures of large solar PV power plants in India, of up to $120 \mathrm{~kW}$ installed capacity. This was larger than any other solar PV installation in Kenya up to that time in 2010.

As the responsible engineer put it seven years later:

"The savings on fuel replaced by solar energy were encouraging and soon after the commissioning of the pilot project, the Ministry of Energy provided more funds for additional five diesel based mini-grids to be hybridized with solar with capacities of $30 \mathrm{kWp}, 50 \mathrm{kWp}$, $2 \times 60 \mathrm{kWp}$ and $300 \mathrm{kWp}$. Following commissioning of these additional solar plants the Ministry of Energy made a decision to hybridize all the existing diesel based mini-grids, 23 in total, and all future mini-grids to be designed as hybrid or pure solar based."

This example shows how the transfer project fed into broader, complex, ongoing processes of sociotechnical system transformation that had gradually opened up a window of opportunity. The transfer project was only one of the reasons for the hybridization projects. The interest in the solar PV technology had been increasing over the recent years, it had become part of policy planning documents in Kenya, and the costs of solar cells had decreased constantly over many years. The government was also eager on innovations that could use renewable energy to reduce fuel costs for the isolated power grids. The learning and inspiration from the technology transfer project interacted with these larger trends and worked as a catalyst.

The Kenyan government's successful "hybridization" of the diesel operated, large "mini-grids" in Kenya contributed to normalizing solar PV as part of the government's work, i.e. to institutionalize this way of using solar PV. Around 2015, solar PV appeared in the Kenya Power statistics on power generation for the first time, and the pioneering engineer expressed that "solar has become part of life" in the governments work on isolated power grids, which involves both the Ministry of Energy and Kenya Power.

The other activity focused on lantern renting and phone charging. The project group assisted on developing the solar charging station model further before the government would implement 840 
charging stations with 24000 portable lights. However, implementation of this project faced several delays

- Kenya Power's department for off-grid power stations was busy with other work, including the hybrid power plants, and procurement processes were lengthy. Not least, Kenya Power leaders still perceive lantern charging as outside their responsibility as power company and not contributing to their business. By April 2017 the project was halfway implemented.

\section{Success factors of the transfer process}

We can identify a number of factors and pre-conditions for the success of the transfer of village-scale solar energy from India to Kenya which are of general relevance for the strategic transfer of innovations between countries with similar needs and interests despite differences in cultures, policies, government structures and geographical features.

1) Embedding the innovation in Kenyan efforts to increase renewable energy use

One of the reasons for the outcomes of the transfer process was that the activity was becoming part of an ongoing system transformation in Kenya. Kenyan renewable energy experts felt the need for new ways of using the solar PV technology in the country, and like the Ikisaya village community they found that the project had the potential to add useful experience. The Kenyan team members had relevant background knowledge, because the activity built on their previous work and their ideas for new steps forward, and they were eager to increase their knowledge on solar energy solutions. They were therefore able to collect relevant knowledge in India and to bring it back to Kenya, use it there, and also share it with others and suggest new initiatives. The fact that significant parts of the project planning in Kenya took place before the examples in India were studied also led to a better integration in the Kenyan renewable energy field. The problem framing, i.e. the articulation of interest in mini-grids as solutions for village-scale supply and provision of higher-grade electricity services than through home systems, was developed in Kenya and "rooted" the transfer project in this country before other steps of the transfer strategy took place.

2) Joint learning and experimentation

An important reason for the project outcomes was that the joint, long-term cooperation of the team created an arena for brainstorming and exchange of knowledge and experience between people from different countries and cultures, from different disciplines, areas of expertise, and between local ("grassroots") and expert knowledge. There was fruitful, social team-building happening between this diversity of actors, through many steps of the projects. Without this close interaction and cooperation, it is very likely that the joint learning and socio-technical innovation would have been poorer. The joint 
learning focused on socio-technical designs for the Kenyan projects and the variety of factors that influenced the practice of using these technologies, including intangible aspects such as motivation, gender roles, leadership, trust, creativity, economic incentives and social control. Learning also took place on how to integrate socio-technical designs with various features of the social context (e.g. capacity to pay, experiences with jointly organizing infrastructure projects in the village), and on desirable qualities of village-level electricity projects, highlighting difficult dilemmas. The differences in the socio-cultural and geographical contexts in India and Kenya moreover gave rise to a more fundamental double-loop learning (Argyris 1999), which means that the Kenyan actors not just learned to apply a technology earlier used in India, but were also triggered to reflect about the pre-conditions of the use of this technology and to make changes in its socio-technical configuration in order to make it work in Kenya. More concretely this refers to the transformation of the original idea and Indian examples of mini-grids to the village energy centre in Ikisaya which gives evidence of a fundamental learning process. The precondition which led to these joint reflection and learning processes was a set of related problems (poverty, energy access etc.), a creative and non-hierarchical interaction of the groups in India and in Kenya, and at the same time sufficiently different context conditions which required different types of solution. A greater similarity of place-specific contexts could rather have led to learning that was more than imitation or replication of existing solutions.

3) Enhanced learning processes through social science involvement

Moreover, these learning processes were enhanced by the involvement of social science. Shifting between academic tasks and the practitioners' requirements provided contrasting perspectives. The social science led, trans-disciplinary project was different from the projects that the practitioners were used to, and created frictions as well as humor and friendly rivalry. Social science research on the local, socio-cultural context before implementation of the Ikisaya Energy Centre in Kenya contributed to processes of "translating" and "re-contextualizing" knowledge and experience from India. After implementation in Kenya the social science contributions helped monitor and analyze the outcomes as a basis for improvements. Social science results were co-produced with other ways of forming the team's understanding, including practitioners' observations and local actors' contributions.

\section{4) Symmetric capacity building}

Importantly, the reason for having participants from the North was not to do "capacity building" in the South, but to create a joint transfer project and research activity with the Kenyan and Indian team members. One of the Kenyan team members commented it like this: "The beauty of the Solar Transitions 
project is that we are all learning together." There was mutual capacity building between all the team members, because the new knowledge obtained by the involved people from different parts of the world (both the North and the South) was created by the long-term collaboration to solve common tasks within research and practice.

\section{Conclusions and policy implications}

Our analysis supports the claim that spatial transfer of innovations between countries in the global South is possible and valuable, and provides lessons on how a context-sensitive transfer and translation of innovations can be achieved. A number of insights relevant for other transfer projects and for policies aiming at the diffusion of sustainable energy innovations across countries can be identified.

Our first point is that the thinking about the transfer of technologies has to be reversed in terms of viewing countries and people in the South as pure recipients of technology. Most of the literature on technology transfer indicates movement in just one direction: from a donor to a recipient. Our research suggests that transfer of innovations can create successful learning processes when it starts out from the situation, problems and needs in the adopter country. The activity can thereby, already from the outset, be embedded in a context of relevant, interested actors and emerging technology sectors in this place. Instead of asking how innovations can be transferred to another place, we should ask "how can countries like Kenya get the chance to learn from achievements (and problems) in other places that they find to be relevant?"

Secondly, the transfer of innovations and socio-technical experimentation are not separate strategies to achieve systemic change, but rather different dimensions of the same learning process. Our analysis has provided an empirical example of how transfer of innovations may take place in ways that facilitate a creative learning process by combining the knowledge of actors with different kinds of knowledge. Spatial transfer of innovations may strengthen socio-technical experimentation and system building by providing new inspiration, ideas, knowledge, networks, experiences and access to technological devices. Sociotechnical experimentation and attempts of system building is a pre-condition for learning between geographical contexts. Sufficient flexibility and openness by the involved actors including those who fund the work is required to accept that the outcome of such experiments and learning may significantly differ from the original transfer intentions. 
A third insight is that a diversity of perspectives is fruitful in learning from other places. Spatial transfer of innovations can provide a rich diversity of perspectives and contrasts that stimulate mutual and joint learning processes through close collaboration between people who represent different world regions, different kinds of knowledge, different project experience, different genders and life experience. Moreover, mutual challenging between practitioners' hands-on experience and social scientist's more abstract approaches can stimulate new ways of thinking and fruitful negotiations between participants.

However, as a final insight of the project, one should not assume that learning from other places and countries is an option available to all. There are barriers for such learning, and there are considerable global differences between actors' opportunities to study socio-technical innovations in other places and countries due to practical and economic hindrances. Freedom to travel is a privilege that is taken for granted among many in the North, while it is not an available option for most people in the South. Lack of contacts and networks in other countries can also be a barrier for international knowledge sharing. Funding for such learning and experimentation is hardly available, and we recommend that global organizations as well as research funders address such hindrances.

Policies aiming at the transfer of sustainable energy innovations between different countries should be developed more systematically and can clearly make a difference. Our analysis suggests that it may be fruitful to put sufficient resources into processes of inter-cultural learning, exchange of experiences and socio-technical experimentation accompanying the transfer of energy innovations. As our example of Kenyan village-scale PV-solutions has amply demonstrated, a better social embedding and adaptation of the new energy solution to the concrete situation, need and socio-cultural context of the recipient countries leads to increased chances of the diffusion and up-scaling of the innovation in this country. A transfer policy which puts more emphasis on these socio-cultural dimensions of technology transfer and which accordingly also acknowledges the value of learning and exchange between countries in the South, might require higher initial investments in human resources and time. If these investments lead to more robust and adapted supply models which can be applied elsewhere in the country, they may in the end much more effectively contribute to the up-take and impact of the energy innovation it supports.

Our study has been limited to one particular technology transfer process between to specific countries in the Global South. However, the characteristics of the learning processes found in this constellation - a process driven by engaged actors in the recipient country; similar problem situations at both sides of the transfer process; a creative, non-hierarchic exchange and learning process; adaptation of the sociotechnical design to the specific contexts in the recipient country; openness to further adaptations and 
learning in the use phase of the technology - make it very likely that such a type of South-South transfer process can be equally useful between other countries of the Global South and with other energy innovations. At the same time the project gives evidence that also countries from the Global North can meaningfully participate in such a transfer process, e.g. by facilitating learning and providing additional resources, though not in the role as a donor of innovative technologies which are then meant to be implemented in recipient countries in the South.

\section{Acknowledgements}

We want to thank the Research Council of Norway for funding two subsequent trans-disciplinary and international research projects that enabled the practical and academic learning process described above and the analysis of the process. (Projects number 190138 and 217137.) Thanks also to everyone who carried out the transfer process and those who are taking it forward through pioneering work on the use of solar PV technology in Kenya, including the partners in Ikisaya village.

\section{References}

Ahlborg, H. (2015). Walking along the lines of power. A systems approach to understanding co-emergence of society, technology and nature in processes of rural electrification. PhD thesis. Göteborg, Sweden: Chalmers University of Technology, Department of Energy and Environment.

Argyris, C. (1999). On Organizational Learning. Cambridge, MA: Blackwell Publishing.

Bell, M. \& Albu, M. (1999). Knowledge Systems and Technological Dynamism in Industrial Clusters in Developing Countries. World Development, 27 (9): 1715-1734.

Berkhout, F., Verbong, G., Wieczorek, A. J., Raven, R., Lebel, L. \& Bai, X. (2010). Sustainability experiments in Asia: innovations shaping alternative development pathways? Environmental Science \& Policy, 13 (4): 261-271.

Bridge, G., Bouzarovski, S., Bradshaw, M. \& Eyre, N. (2013). Geographies of energy transition: Space, place and the low-carbon economy. Energy Policy, 53: 331-340.

Byrne, R. P. (2009). Learning drivers - Rural electrification regime building in Kenya and Tanzania. UK: PhD dissertation. University of Sussex.

Byrne, R., Smith, A., Watson, J. \& Ockwell, D. (2011). Energy Pathways in Low-Carbon Development: From Technology Transfer to Socio-Technical Transformation. Working Papers from the STEPS Centre. Brighton, UK: University of Sussex.

Coenen, L., Benneworth, P. \& Truffer, B. (2012). Toward a spatial perspective on sustainability transitions. Research Policy, 41 (6): 968-979.

Coenen, L., Raven, R. \& Verbong, G. (2010). Local niche experimentation in energy transitions: A theoretical and empirical exploration of proximity advantages and disadvantages. Technology in Society, 32 (4): 295-302.

Fuenfschilling, L. \& Truffer, B. (2014). The structuration of socio-technical regimes-Conceptual foundations from institutional theory. Research Policy, 43 (4): 772-791.

Geels, F. \& Raven, R. (2006). Non-linearity and expectations in niche-development trajectories: Ups and downs in dutch biogas development (1973-2003). Technology Analysis \& Strategic Management 18: 375-392. 
Grübler, A. \& Nakićenović, N. (1991). Long Waves, Technology Diffusion, and Substitution. Review (Fernand Braudel Center), 14 (2): 313-343.

GTZ. (2009). Kenya's Solar Energy Market - Target Market Analysis Berlin, Germany: Project Development Programme (PDP) East Africa. Deutsche Gesellschaft für Technische Zusammenarbeit (GTZ) on behalf of the German Federal Ministry of Economics and Technology (BMWi).

Halsnæs, K., Shukla, P., D.;, A., Akumu, G., Beale, R., Edmonds, J., Gollier, C., Grübler, A., Ha Doung, M., Markandya, A., et al. (2007). Framing issues. In Metz, B., Davidson, O. R., Bosch, P., Dave, R. \& Meyer, L. (eds) IPCC, 2007: Climate Change 2007: Mitigation of Climate Change. Contribution of Working Group III to the Fourth Assessment Report of the Intergovernmental Panel on climate Change, pp. 117-167. Cambridge, United Kingdom: Cambridge University Press.

Herr, K. \& Anderson, G. L. (2005). The Action Research Dissertation: A Guide for Students and Faculty. London, United Kingdom: Sage Publications.

Hoekman, B., Maskus, K. E. \& Saggi, K. (2004). Transfer of Technology to Developing Countries: Unilateral and Multilateral Policy Options. Policy Research Working Papers, vol. World Bank Policy Research Working paper 3332, June 2004: The World Bank. 36 pp.

Hoogma, R., Kemp, R., Schot, J. \& Truffer, B. (2002). Experimenting for sustainable transport: The approach of strategic niche management. London and New York: Spon Press. 212 pp.

IEA (2017). Energy Access Outlook 2017. From Poverty to Prosperity. Paris: International Energy Agency. $144 \mathrm{pp}$.

Jacobson, A. (2007). Connective Power: Solar Electrification and Social Change in Kenya. World Development, 35 (1): 144-162.

Janda, K. \& Parag, Y. (2013). A middle-out approach for improving energy performance in buildings. Building Research \& Information 41(1): 39-50.

Kalleberg, R. (2009). Can normative disputes be settled rationally? . In Cherkaoui, M., Hamilton, P. \& Boudon, R. (eds) Raymond Boudon: a life in sociology: essays in honour of Raymond Boudon, pp. Vol. 2, pp. 251-269. Oxford, UK: The Bardwell Press.

Karlsen, J. \& Larrea, M. (2014). Territorial development and action research: innovation through dialogue. Farnham, England: Gower Publishing Limited. 198 pp.

Martinot, E., Sinton, J. E., Haddad \& M., B. (1997). International technology transfer for climate change mitigation and the cases of Russia and China. Annual Review of Energy and the Environment, 22 (1): 357-401.

Maskus, K. E. (2004). Encouraging International Technology Transfer. Issue Paper. Geneva, Switzerland.

Metz, B., Davidson, O. R., Martens, J.-W., Rooijen, S. N. M. v. \& McGrory, L. V. W. (2000). Methodological and Technological Issues in Technology Transfer - A special report of IPCC Working Group II. Published for the Intergovernmental Panel on Climate Change. Cambridge, United Kingdom: University of Cambridge. 465 pp.

Murphy, J. T. (2001). Making the energy transition in rural East Africa: Is leapfrogging an alternative. Technological Forecasting and Social Change, 68 (1): 173-193.

Ockwell , D. and Byrne, R. (2017). Sustainable energy for all: Innovation, tcehnology and por-poor green transformations

Raven, R. P. J. M., Heiskanen, E., Lovio, R., Hodson, M. \& Brohmann, B. (2008). The Contribution of Local Experiments and Negotiation Processes to Field-Level Learning in Emerging (Niche) Technologies: Meta-Analysis of 27 New Energy Projects in Europe. Bulletin of Science, Technology \& Society, 28 (6): 464-477.

Reddy, N. M. \& Zhao, L. (1990). International technology transfer: A review. Research Policy, 19 (4): 285307.

Román, M., Linnér, B.-O. \& Mickwitz, P. (2012). Development policies as a vehicle for addressing climate change. Climate and Development, 4 (3): 251-260. 
Romijn, H. A. \& Caniëls, M. C. J. (2011). Pathways of technological change in developing countries: Review and new agenda. Development Policy Review, 29 (3): 359-380.

Russell, S. \& Williams, R. (2002). Social shaping of technology: Frameworks, findings and implications for policy with glossary of social shaping concepts. In Williams, R. \& Sørensen, K. H. (eds) Shaping technology, guiding policy: concepts, spaces and tools. Cheltenham: Edward ElgarSchot, J. \& Geels, F. W. (2008). Strategic niche management and sustainable innovation journeys: theory, findings, research agenda, and policy. Technology Analysis \& Strategic Management, 20 (5): 537-554.

Soete, L. (1985). International diffusion of technology, industrial development and technological leapfrogging. World Development, 13 (3): 409-422.

Späth, P. \& Rohracher, H. (2012). Local Demonstrations for Global Transitions-Dynamics across Governance Levels Fostering Socio-Technical Regime Change Towards Sustainability. European Planning Studies, 20 (3): 461-479.

Stirling, A. (2008). Science, precaution, and the politics of technological risk: converging implications in evolutionary and social scientific perspectives. Annals of the New York Academy of Sciences, 1128: 95-110.

Ulsrud, K., Winther, T., Palit, D., Rohracher, H. \& Sandgren, J. (2011). The Solar Transitions research on solar mini-grids in India: Learning from local cases of innovative socio-technical systems. Energy for Sustainable Development, 15 (3): 293-303.

Ulsrud, K., Winther, T., Palit, D. \& Rohracher, H. (2015). Village-level solar power in Africa: Accelerating access to electricity services through a socio-technical design in Kenya. Energy Research \& Social Science, 5: 34-44.

Wieczorec, A.J. Raven, R., Berkhout, F. (2015), Transnational linkages in sustainability experiments: A typology and the case of solar photovoltaic in India. Environmental Innovation and Societal Transitons 17: 149-165.

World Bank \& IEA. (2013). Global Tracking Framework. Sustainable Energy for All: World Bank and International Energy Agency. 289 pp. 